\title{
Baccharis rufescens Spreng. var. tenuifolia (DC.) Baker: contribuição ao estudo farmacognóstico
}

\author{
SOUZA, J.P'; SANTOS, V.L.P'; FRANCO, C.R.C ${ }^{2}$.; BORTOLOZO, E.A.F.Q. ${ }^{3}$; FARAGO, P.V. MATZENBACHER, \\ N.I. ${ }^{5}$; BUDEL, J.M. ${ }^{4 *}$ \\ ${ }^{1}$ Faculdades Integradas do Brasil, Rua Konrad Adenauer, 442, CEP 82821-020, Curitiba, Brasil. ${ }^{2}$ Centro de \\ Microscopia Eletrônica da Universidade Federal do Paraná, Av. Pref. Lothário Meissner, 632, CEP: 80210-170, \\ Curitiba, Brasil. ${ }^{3}$ Universidade Tecnológica Federal do Paraná, Av. Monteiro Lobato, km 4, CEP: 84016-210, \\ Ponta Grossa. ${ }^{4}$ Departamento de Ciências Farmacêuticas, Universidade Estadual de Ponta Grossa, Av. Carlos \\ Cavalcanti, 4748, CEP: 84030-900, Ponta Grossa, Brasil. ${ }^{5}$ Programa de Pós-graduação em Botânica, Pontifícia \\ Universidade Católica do Rio Grande do Sul, Av. Ipiranga, 6681, CEP: 90619-900, Porto Alegre, Brasil *e-mail \\ janemanfron@hotmail.com
}

\begin{abstract}
RESUMO: Baccharis rufescens Spreng. var. tenuifolia (DC.) Baker pertence à família Asteraceae e é usada na medicina tradicional como estomáquico e hepatoprotetor. Um estudo fitoquímico mostrou a presença de flavonoides e triterpenos, sendo que os extratos clorofórmico e metanólico de folhas apresentaram-se ativos no bioensaio de toxicidade sobre Artemia salina Leach. Além disso, extratos clorofórmicos evidenciaram a presença de peróxidos, sugerindo sua aplicação no tratamento da malária (Schenkel at al., 2002; Montanher et al., 2002; Moreira et al., 2003). Considerando a importância farmacológica de $B$. rufescens var. tenuifolia, o presente trabalho objetivou o estudo morfoanatômico e histoquímico do caule e da folha dessa espécie, a fim de fornecer subsídios farmacognósticos para o controle de qualidade. O material botânico foi submetido às técnicas usuais empregadas na microscopia de luz e microscopia eletrônica de varredura. Folha anfiestomática, presença de estômatos anomocíticos, tricomas glandulares capitados bisseriados, tricomas tectores flageliformes simples unisseriados, dutos secretores associados ao floema, calota de fibras perivasculares e cristais de oxalato de cálcio do tipo estiloide e prismático na região medular do caule foram as principais características observadas que auxiliam na identificação do táxon.
\end{abstract}

Palavras-chave: Asteraceae, Baccharis, Baccharis rufescens Spreng. var. tenuifolia (DC.) Baker, farmacognosia

ABSTRACT: Baccharis rufescens Spreng. var. tenuifolia (DC.) Baker: contribution to the pharmacognostic study. Baccharis rufescens Spreng. var. tenuifolia (DC.) Baker belongs to the Asteraceae family. It is used for liver and stomach problems in traditional medicine. Previous phytochemical data reported flavonoid and triterpene contents. Chloroform and methanol extracts of the leaves showed activity in the bioassay of brine shrimp. Chloroform extracts showed the presence of peroxides that can be used to treat malaria (Schenkel et al., 2002; Montanher et al., 2002; Moreira et al., 2003). Considering the pharmacological importance of $B$. rufescens var. tenuifolia, the purpose of this paper was to perform the anatomical analysis of aerial vegetative parts of Baccharis rufescens var. tenuifolia in order to provide pharmacognostic data for quality control. The plant material was studied by the usual methods of light and scanning electron microscopy. Amphistomatic leaves, anomocytic stomata, biseriate capitate glandular trichomes, uniseriate simple flagelliform non-glandular trichomes, secretory ducts associated to the phloem, perivascular fiber cap, calcium oxalate as prismatic and styloid crystals in the pith of the stem were reported as the mainly anatomical data for $B$. rufescens var. tenuifolia.Ouvir Ler foneticamente

Keywords: Asteraceae, Baccharis, Baccharis rufescens var. tenuifolia, pharmacognosy

Recebido para publicação em 17/03/2011

Aceito para publicação em 03/03/2013

Rev. Bras. Pl. Med., Campinas, v.15, n.4, p.566-574, 2013. 


\section{INTRODUÇÃO}

Asteraceae é a maior família de Asterales e compreende aproximadamente 1600 gêneros e 23000 espécies. No Brasil, ocorrem cerca de 300 gêneros e 2000 espécies. Dentre os gêneros mais importantes está Baccharis L., que compreende cerca de 400 espécies. Atualmente, são reconhecidas cerca de 150 espécies ocorrentes no Brasil e aproximadamente 120 na região Sudoeste do país (Judd et al., 1999; Souza \& Lorenzi, 2005; Oliveira et al., 2006).

Levantamentos etnobotânicos realizados em diversas comunidades sulamericanas que utilizam plantas para o tratamento de enfermidades, indicam o uso de representantes de Baccharis principalmente como analgésico, diurético, espasmolítico, antidiabético, anti-infeccioso e estomáquico. Nesse sentido, extratos de diversas espécies de Baccharis têm demonstrado diferentes ações farmacológicas (Avancini et al., 2000; Feresin et al., 2001; Baggio et al., 2003; Oliveira et al., 2003; Verdi et al., 2005; Simões-Pires et al., 2005; Budel et al., 2008). Investigações da atividade do óleo essencial de espécies de Baccharis evidenciaram ação antifúngica, antibacteriana e repelente (Cobos et al., 2001; Demo et al., 2005).

Baccharis rufescens Spreng. var. tenuifolia (DC.) Baker é o nome atual do binômio Baccharis pseudotenuifolia Teodoro que foi corrigido taxonomicamente no trabalho de Matzenbacher et al. (2011). É usada na medicina tradicional como estomáquico e hepatoprotetor (Montanher et al., 2002). Estudo fitoquímico mostrou a presença de flavonoides, triterpenos, e os extratos clorofórmico e metanólico de folhas desta espécie apresentaramse ativos no bioensaio de toxicidade sobre Artemia salina Leach (Montanher et al., 2002; Moreira et al., 2003). Extratos clorofórmicos de

B. rufescens var. tenuifolia evidenciaram a presença de peróxidos em trabalho de Schenkel et al. (2002), sugerindo sua aplicação no tratamento da malária.

A pesquisa de espécies vegetais medicinais tem demonstrado a importância de estudos integrados às diversas áreas da ciência. A morfoanatomia contribui para o conhecimento desses vegetais, principalmente, em se tratando da correta identificação da espécie. A diagnose de espécies medicinais baseia-se primeiramente na análise morfoanatômica dos órgãos vegetativos e reprodutivos, mostrando-se relevante na identificação de drogas pulverizadas ou rasuradas, contribuindo para o controle da qualidade de drogas vegetais (Donato \& Morretes, 2005).

Inúmeras espécies de Baccharis, usadas como medicinais, ainda não foram estudadas cientificamente. As evidências químicas, botânicas e farmacológicas permitem um estudo mais aprofundado dessas espécies, contribuindo para o desenvolvimento de fitoterápicos, bem como para evitar intoxicações e o uso de plantas que não tenham efeito sobre processos patológicos que se pretenda combater (Budel et al., 2005).

Desta forma, considerando a importância terapêutica de Baccharis rufescens var. tenuifolia, o presente trabalho objetivou o estudo morfoanatômico e histoquímico do caule e da folha deste táxon.

\section{MATERIAL E MÉTODO}

Foram coletadas partes aéreas floridas de pelo menos 5 exemplares de Baccharis rufescens var. tenuifolia, em Guaíba ( $30^{\circ} 10^{\prime} \mathrm{S}$ e $51^{\circ} 20^{\prime} \mathrm{W}$ ), $27 \mathrm{~m}$ de altitude), Rio Grande do Sul. Os exemplares foram submetidos à confecção de exsicatas, identificadas por especialista e os representantes equivalentes estão registrados no Herbário de Biociências da UFRGS sob o número ICN 53573. O material coletado foi devidamente processado para a realização do estudo anatômico.

\section{Estudo Anatômico}

As pesquisas referentes aos caracteres morfoanatômicos foram efetuadas com folhas e caules de Baccharis rufescens var. tenuifolia, a partir de $5 \mathrm{~cm}$ do ápice da planta. O material vegetal foi fixado em FAA 70 (formol 5\%, ácido acético $5 \%$ e etanol $70^{\circ} \mathrm{GL} 90 \% \mathrm{v} / \mathrm{v}$ ) (Johansen, 1940), e estocados em solução de etanol a $70 \%$ (v/v) (Berlyn \& Miksche, 1976).

Foram preparadas Iâminas semipermanentes com o material seccionado nos sentidos transversal e longitudinal, à mão livre, submetido à coloração de azul de astra e fucsina básica (ROESER, 1972) ou de azul de toluidina (O'BRIEN, FEDER, MCCULLY, 1964). As lâminas foram montadas com glicerina diluída a $50 \%(\mathrm{v} / \mathrm{v})$ (BERLYN, MIKSCHE, 1976) e para a lutagem foi utilizado esmalte incolor.

Para a preparação das lâminas permanentes, utilizou-se a técnica de inclusão em glicol metacrilato (FEDER, O'BRIEN, 1968). Empregou-se o material previamente fixado e armazenado em etanol a $70 \%$ $(\mathrm{v} / \mathrm{v})$. O material foi seccionado no plano transversal em micrótomo de rotação Spencer 820, obtendo-

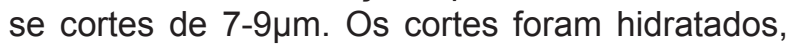
distendidos em lâminas e secos em mesa térmica a $40^{\circ} \mathrm{C}$. Para a coloração empregaram-se azul de astra e fucsina básica (BRITO, ALQUINI, 1996).

\section{Testes Histoquímicos}

Foram realizadas secções transversais à mão livre de folhas e caule de Baccharis

Rev. Bras. PI. Med., Campinas, v.15, n.4, p.566-574, 2013. 
rufescens var. tenuifolia e os reativos empregados foram solução de floroglucina clorídrica para verificação de lignina (Foster, 1949), Sudam III para substâncias lipofílicas (Sass, 1951), cloreto férrico para compostos fenólicos (Johansen, 1940) e lugol para amido (Berlyn \& Miksche, 1976).

Os resultados dos testes histoquímicos e da análise anatômica foram registrados por meio de fotomicrografias em microscópio fotônico Olympus BX 40, acoplado à unidade de controle PM-20.

\section{Microscopia eletrônica de varredura - MEV}

A caracterização morfológica das superfícies caulinares e foliares de Baccharis rufescens var. tenuifolia foi realizada com análise ao microscópio eletrônico de varredura.

Para tal procedimento, as amostras foram fixadas em FAA 70, desidratadas em série etanólica crescente e pelo ponto crítico no equipamento Balzers CPD-010 e, após montagem em suporte metálico, submetidas à metalização com ouro, em aparelho Balzers Sputtering SCD-030. As eletromicrografias foram realizadas em microscópio eletrônico de varredura Phillips SEM 505 (SOUZA, 1998).

\section{RESULTADO}

A análise anatômica da lâmina foliar de Baccharis rufescens var. tenuifolia (Figura 1A), em vista frontal, mostra células epidérmicas com parede anticlinal de formato levemente curvado (Figura 1B), em ambas as faces, e campos de pontuação primária podem ser observados. A ornamentação cuticular é levemente estriada (Figura 1C), em ambas as faces. Os estômatos são do tipo anomocítico (Figura 1B), aparecendo em ambas às faces epidérmicas, caracterizando a folha como anfiestomática.

Em secção transversal, a epiderme apresenta-se uniestratificada (Figuras 2A, 2B, 2D), coberta por cutícula delgada (Figura 2D). Os estômatos estão localizados no mesmo nível das demais células epidérmicas (Figura 2D). Tricomas, tanto tectores (Figura 1D), quanto glandulares (Figura 1E), podem ocorrer isolados ou em tufos (Figura 1E), e frequentemente, estão localizados em depressão na epiderme.

Os tricomas glandulares (Figura 1E), capitados bisseriados são constituídos de 8-12 células, recobertos por cutícula evidente e com citoplasma denso. Considerando os testes histoquímicos, os tricomas glandulares reagem positivamente à pesquisa de compostos lipofílicos. Os tricomas tectores são do tipo flageliformes simples unisseriados, formados por cerca de 3-5 células que se alargam em direção ao ápice. Quanto à célula terminal, estes a apresentam alongada em forma de flagelo (Figura 1D).

O mesofilo é isobilateral, sendo constituído pelo parênquima paliçádico atípico, com células relativamente curtas, dispostas em aproximadamente 1-4 estratos junto às superfícies epidérmicas, e pelo parênquima esponjoso estreito e formado por cerca de 2-3 camadas, estabelecendo pequenos espaços intercelulares (Figuras 2A, 2B, 2E).

Feixes vasculares de pequeno porte, do tipo colateral, estão distribuídos na região mediana do mesofilo (Figuras 2A, 2B, 2E), são envoltos por bainha parenquimática e podem estar associados a dutos secretores, que se dispõem externamente ao floema. Os dutos secretores apresentam epitélio unisseriado (Figura 2D), formado por cerca de 6-8 células, com citoplasma denso e núcleo evidente, e secretam substância de natureza lipofílica.

A nervura principal, em secção transversal, possui formato levemente côncavo na face adaxial e sutilmente convexo na face abaxial (Figura 2B). A epiderme uniestratificada é revestida por cutícula levemente estriada e, subjacente, ocorrem 1-2 camadas de colênquima angular, em ambas as faces. Na região central da nervura, evidencia-se um feixe vascular colateral apresentando uma calota de fibras perivasculares aposta ao xilema e ao floema (Figura 2C).

O caule, seccionado transversalmente, apresenta formato circular irregular com cerca de 6 saliências (Figura 3A). A epiderme caulinar apresenta-se uniestratificada. A cutícula do caule é delgada e levemente estriada e reagiu positivamente à pesquisa de compostos lipofílicos. Da mesma forma que na folha, ocorrem tricomas glandulares e tectores.

Adjacente à epiderme, em secção transversal, principalmente na região das saliências, encontram-se cerca de 2-8 camadas de colênquima (Figura 3C). Em posição externa ao floema, dutos secretores, de epitélio unisseriado, formado por 4-10 células, são observados (Figura 3C). Calotas de fibras perivasculares estão apostas ao floema (Figura 3C). Fibras podem ser observadas no sistema floemático (Figuras 3B, 3C).

A região medular possui parênquima com células relativamente grandes e de paredes delgadas. $\mathrm{Na}$ zona perimedular podem ser encontrados cristais de oxalato de cálcio do tipo estiloide e prismático de diversos tamanhos (Figura 3D).

\section{DISCUSSÃO}

Ariza-Espinar (1973) afirmou que a epiderme sempre está coberta por cutícula espessa 

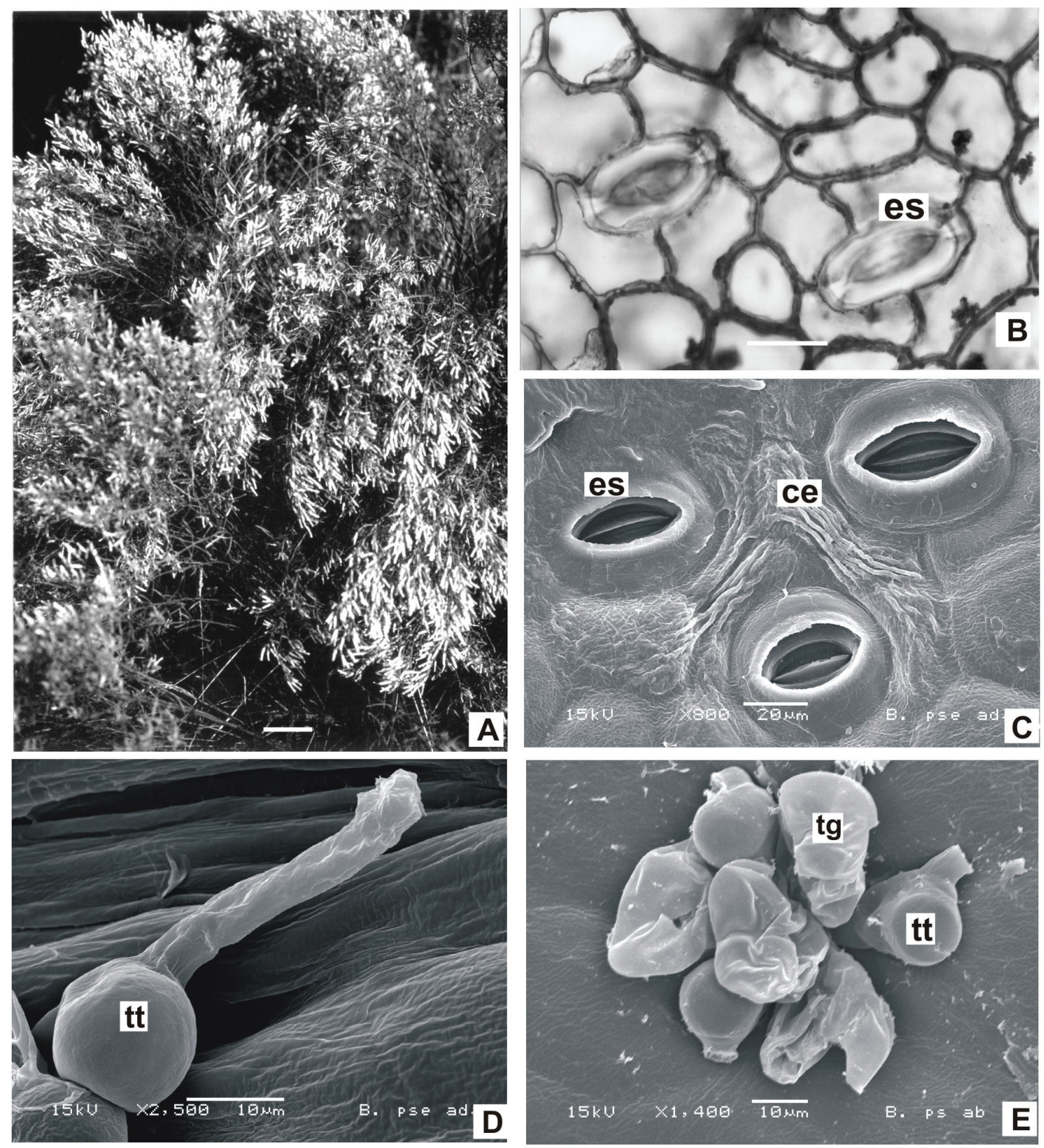

FIGURA 1. Baccharis pseudotenuifolia Malag., Asteraceae: A - Aspecto geral; B - Vista frontal da epiderme foliar, face adaxial, mostrando estômatos anomocíticos e contorno das células epidérmicas; C - Vista frontal da epiderme da face adaxial, evidenciando estômatos e cutícula estriada (MEV); D - Vista frontal da epiderme da face abaxial, mostrando o tufo de tricomas com tricomas tectores e glandulares (MEV); E - Vista frontal indicando tricoma tector flageliforme simples (MEV). ce = cutícula estriada; es = estômato; $\mathrm{tg}=$ tricoma glandular capitado bisseriado; $\mathrm{tt}=$ tricoma tector flageliforme simples Barra = $5 \mathrm{~cm}(\mathrm{~A}) ; 50 \mu \mathrm{m}(\mathrm{B})$.

em Baccharis e que esta pode proporcionar características muito particulares, como em $B$. articulata, que ao redor dos tricomas mostra estriações radiais e, nas células subsidiárias, concêntricas. Em B. rufescens var. tenuifolia, a cutícula mostrou-se delgada e levemente estriada tanto na folha, quanto no caule. É importante destacar que cutícula espessa é uma característica anatômica que pode variar com o ambiente (Jorge,
2000).

Metcalfe \& Chalk (1950) reconheceram quatro tipos básicos de estômatos em Magnoliopsida: anomocítico, anisocítico, paracítico e diacítico. Outros 14 tipos, mais tarde, foram classificados, como por exemplo, actinocítico, ciclocítico, pericítico, desmocítico, polocítico, estaurocítico e tetracítico (Baranova, 1987). Tendo-se adotado essa classificação, na espécie analisada foi encontrado 

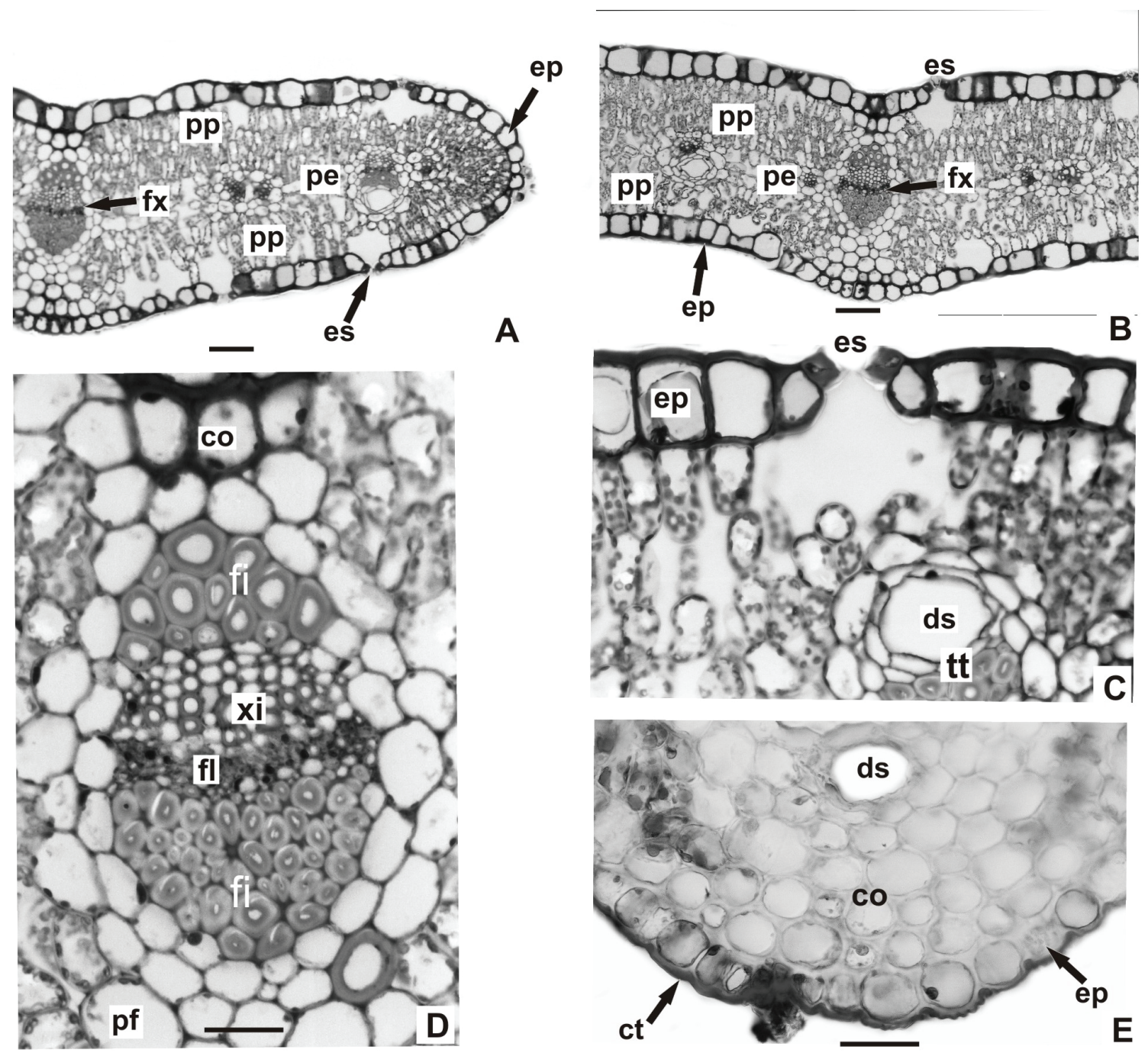

FIGURA 2. Baccharis pseudotenuifolia Malag., Asteraceae - Secção transversal da folha. A - Formato levemente côncavo-convexo da nervura central, mesofilo isobilateral e bordo foliar; B - Nervura central e mesofilo; C - Detalhe da nervura central, evidenciando feixe vascular único central e calotas de fibras vasculares aposta ao floema e xilema; D - Epiderme uniestratificada, estômato e duto secretor; Secção transversal do caule. $E$ - Colênquima, duto e epiderme da nervura central. $E p=$ epiderme, es = estômato, $\mathrm{ct}=$ cutícula, $\mathrm{co}=$ colênquima, $\mathrm{ds}=$ duto secretor, ep = epiderme, $\mathrm{fi}=\mathrm{fibras}, \mathrm{fl}=\mathrm{floema}, \mathrm{fx}=$ feixe vascular, $\mathrm{pe}=$ parênquima esponjoso, $\mathrm{pp}=$ parênquima paliçádico, $\mathrm{tt}=$ tufo de tricomas, $\mathrm{xi}=$ xilema. Barra $=50 \mu \mathrm{m}$.

estômato anomocítico.

Esse resultado corresponde ao mencionado para B. coridifolia DC.,

B. rufescens Spreng., B. rupestris Heering, B. flabellata Hook. \& Arn., B. salicifolia (Ruiz \& Pav.) Pers. e B. pingraea DC. (Ariza-Espinar, 1973), B. articulata (Lam). Pers. (Ariza-Espinar, 1973; Cortadi et al., 1999), B. crispa Spreng. (Ariza-Espinar, 1973; Cortadi et al., 1999; Budel et al., 2004a). B. gaudichaudiana DC. (Budel et al., 2003), B. trimera (Less.) DC. (F. BRAS. IV, 1988-2003), B. uncinella DC. (Budel \& Duarte, 2008a) e B. usterii Heering (Budel \& Duarte, 2010).

A descrição dos tricomas constitui característica de grande valia na diagnose da droga vegetal, principalmente quando se apresenta fragmentado ou mesmo pulverizado

(Freire et al., 2007). Em folhas de Asteraceae, podem ser encontrados vários tipos de estruturas secretoras, como dutos, cavidades, idioblastos, laticíferos, hidatódios, nectários extraflorais e tricomas glandulares (Castro et al., 1997, Budel et al., 2009),. Na espécie analisada, foram observados somente tricomas glandulares e dutos secretores, levando-se em conta que foram analisados apenas órgãos vegetativos aéreos.

Tricomas glandulares bisseriados têm sido frequentemente encontrados em diferentes tribos de 


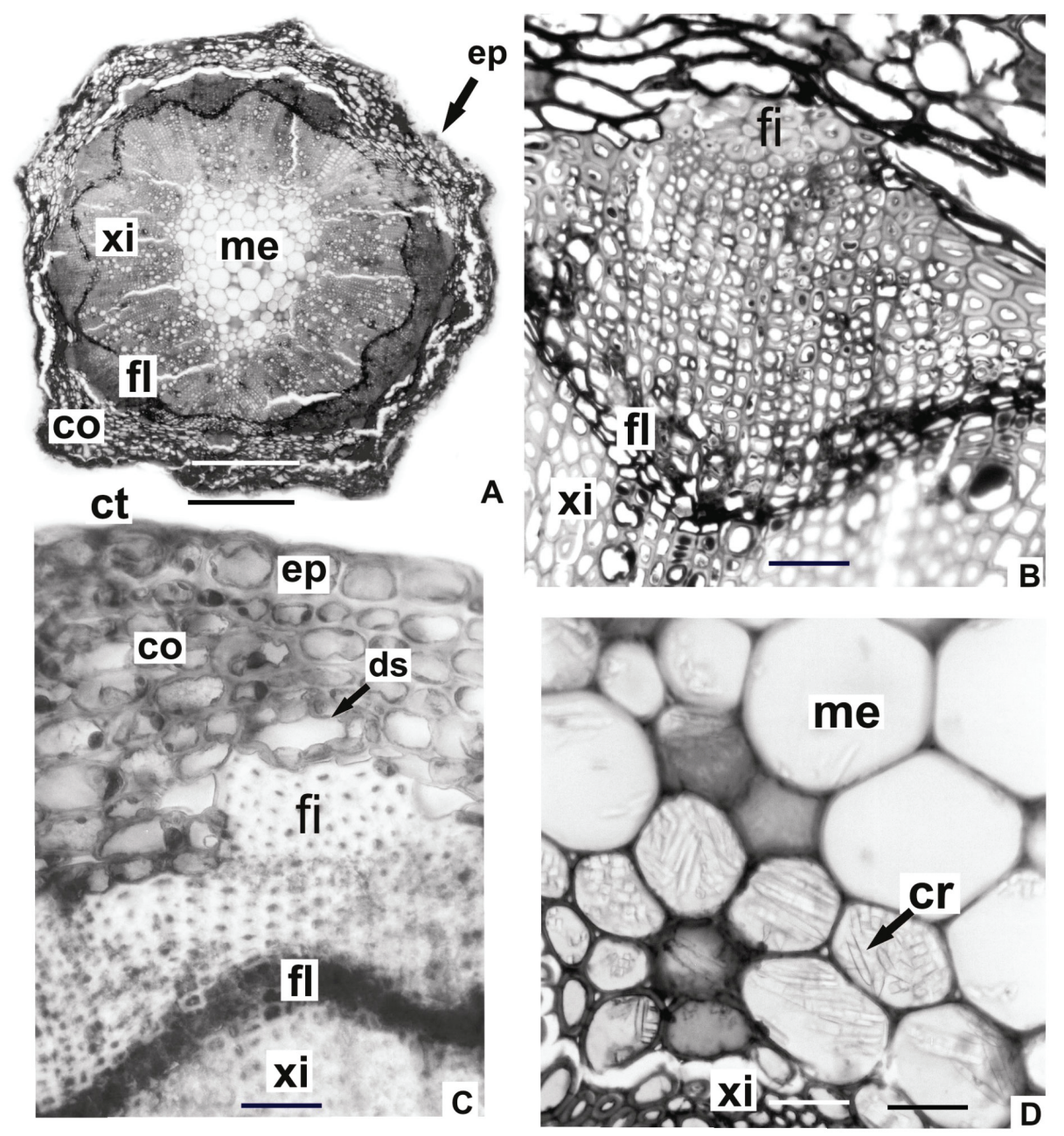

Figura 3. Baccharis rufescens Spreng. var. tenuifolia (DC.) Baker

(Asteraceae). Secção transversal do caule. A - Aspecto geral do caule evidenciando aspecto circular irregular; B - Presença de fibras no floema; $C$ - Detalhe do caule, evidenciando epiderme com cutícula, colênquima angular, duto secretor, floema e xilema; D - Presença de cristais de oxalato de cálcio na zona perimedular. ct: cutícula, co: colênquima, cr: cristais de oxalato de cálcio, ds: duto secretor, ep: epiderme, fi: fibras, fl: floema, me: medula, xi: xilema. Barra $=50 \mu \mathrm{m}$.

Asteraceae (Ariza-Espinar, 1973; Werker \& Fahn, 1981; Peterson \& Vermeer, 1984; Castro et al., 1997; Cortadi et al., 1999; Pagni, \& Masini, 1999; Budel et al., 2006; Freire et al., 2007; Rodriguez et al., 2008; Budel et al., 2009). Tricomas glandulares são encontrados isolados, entretanto, frequentemente podem aparecer em tufos e em depressão na epiderme na espécie avaliada. Esses dados estão de acordo com os relatos de Freire et al. (2007); Petenatti et al. (2007) e Rodriguez et al. (2008) em relação ao indumento de Baccharis.

Tricomas tectores pluricelulares unisseriados, com base formada de 2-8 células e diferindo quanto à morfologia da célula apical, que pode ser medianamente alongada a flageliforme foram observados em Baccharis (Ariza-Espinar, 1973; Freire et al., 2007). Na espécie estudada, o tipo flageliforme simples mostrou-se frequente. De acordo com Freire et al. (2007), a análise do indumento de Baccharis contribuiu na diagnose da droga vegetal.

Werker (2000) afirma que não existe nenhuma classificação totalmente satisfatória para os tricomas. Neste estudo, a morfologia foi utilizada como critério de classificação dos tricomas. Entretanto, os tricomas tectores flageliformes simples apresentaram as células da base com citoplasma denso, núcleo evidente e que reagiram positivamente à pesquisa de compostos lipofílicos. Nesse contexto, acredita-se que esses tricomas desempenhem simultaneamente função protetora $e$ secretora, e que, de acordo com essas características funcionais, possam ser classificados também como tricomas mistos. 
O mesofilo apresenta-se diferenciado em parênquima paliçádico e esponjoso em várias espécies de Asteraceae (Toigo et al., 2004; Milan et al., 2006). Nesse sentido, o arranjo dos parênquimas fotossintetizantes da folha de $B$. rufescens var. tenuifolia apontou mesofilo isobilateral. A disposição isobilateral dos parênquimas fotossintetizantes está em correspondência ao descrito para as folhas de B. dracunculifolia (Budel et al., 2004a; Pegorini et al., 2008), B. uncinella (Budel \& Duarte, 2008a) e B. usterii (Budel \& Duarte, 2010).

Em Asteraceae, a endoderme pode apresentar estria de Caspary, o que caracteriza a endoderme típica, ou pode conter amido, sendo referida como bainha amilífera (Metcalfe \& Chalk, 1950; Esau, 1976). Para Ariza-Espinar (1973), a endoderme é comum em caule e raiz de Asteraceae. Segundo esse autor, em Baccharis, não ocorrem estrias de Caspary.

Delimitando internamente a região cortical, uma endoderme sem estrias de Caspary visíveis foi observada na espécie em estudo. Nas proximidades dessa endoderme, observaram-se dutos secretores formados por aproximadamente 6-8 células em epitélio único. Estes foram relatados para os caules do gênero Baccharis por diferentes autores (ArizaEspinar, 1973; Cortadi et al., 1999; Budel et al., 2003; 2004a; Budel \& Duarte, 2008a, 2009, 2010; Budel et al., 2012).

Oliveira et al. (1993) afirmaram que uma característica relevante na diagnose das drogas vegetais é a calota de fibras localizada sobre o sistema vascular. Nesse sentido,

B. pseudotenuifolia var. pseudotenuifolia evidenciou essa calota em aposição ao floema.

De acordo com Pagni \& Masini (1999), em muitos membros de Asteraceae, os dutos estão frequentemente relacionados com a endoderme ou com o sistema vascular. Nesse aspecto, $B$. rufescens var. tenuifolia exibiu dutos secretores em posição externa ao floema, e os feixes vasculares colaterais de pequeno porte são envoltos por endoderme, características amplamente relatadas em diversas espécies do gênero (Ariza-Espinar, 1973; Sá \& Neves, 1996; Cortadi et al., 1999; Budel et al., 2003; 2004a; 2004b; Petenatti et al., 2007; Rodriguez et al., 2008; Budel \& Duarte 2008a,b, 2009, 2010; Budel et al., 2012).

Plantas produzem uma variedade de formas e tamanhos de cristais de oxalato de cálcio, que, baseados na morfologia, podem se apresentar como areia cristalina, drusas, ráfides, estiloides e prismas. Usualmente a morfologia do cristal, bem como a distribuição no órgão são conservadas dentro de um táxon específico (Nakata, 2003).

Nesse contexto, na região perimedular da espécie em estudo, evidenciou-se a presença de cristais de oxalato de cálcio de diversas formas. Estes foram amplamente relatados, a saber: em $B$. articulata (Ariza-Espinar, 1973; Cortadi et al., 1999), B. crispa (Cortadi et al., 1999; Budel et al., 2004a), B. gaudichaudiana (Budel et al., 2003),

B. myriocephala (Sá \& Neves, 1996), B. triangularis Hauman (Petenatti et al., 2007), B. trimera (F. BRAS. IV, 1988-2003; Cortadi et al., 1999), B. usterii (Budel \& Duarte, 2010).

As evidências botânicas, como a presença de dutos secretores e tricomas glandulares, incentivam a realização de trabalhos voltados para o isolamento de compostos químicos e ensaios farmacológicos e microbiológicos com as espécies deste trabalho, a fim de se determinar a presença de compostos bioativos.

\section{CONCLUSÃO}

As características mais relevantes observadas na espécie analisada, tais como folha anfiestomática, presença de estômatos anomocíticos, tricomas glandulares capitados bisseriados constituídos de 8-12 células, tricomas tectores flageliformes simples unisseriados, formados por cerca de 3-5 células que se alargam em direção ao ápice, mesofilo isobilateral, dutos secretores associados ao floema, calota de fibras perivasculares e presença de cristais de oxalato de cálcio do tipo estiloide e prismático na região medular do caule, contribuem na diagnose da droga vegetal e fornecem subsídios taxonômicos ao gênero Baccharis e à família Asteraceae.

\section{REFERÊNCIA}

ARIZA-ESPINAR, L.A. Las especies de Baccharis (Compositae) de Argentina Central. Boletin de La Academia Nacional de Ciências, v.50, p.176-305, 1973.

AVANCINI, C.A.M.; WIEST, J.M.; MUNDSTOCK, E. Bacteriostatic and bactericidal activity of the Baccharis trimera (Less.) DC. - Compositae, decocto, as disinfectant or antisseptic. Arquivo Brasileiro de Medicina Veterinária e Zootecnia, v.52, n.3, p.2304, 2000. BAGGIO, C.H. et al. Gastroprotective effects of a crude extract of Baccharis illinita DC. in rats. Pharmacological Research, v.47, p.93-8, 2003.

BARANOVA, M.A. Historical development of the present classification of morphological types of stomats. Botanical Review, v.53, n.1, p. 53-79, 1987.

BERLYN, G.P.; MIKSCHE, J.P. Botanical microtechnique and cytochemistry. Ames: lowa State University, 1976.

BRITO, C. J. F. A.; ALQUINI, Y. A new method for staining botanical material embedded in glycol methacrylate (GMA). Arquivos de Biologia e Tecnologia, Curitiba, v.39, n.4, p. 949-51, 1996.

BUDEL, J.M. DUARTE, M.R.; SANTOS, C.A.M. Caracteres

Rev. Bras. Pl. Med., Campinas, v.15, n.4, p.566-574, 2013. 
morfo-anatômicos de Baccharis gaudichaudiana DC., Asteraceae. Latin American Journal of Pharmacy, v.22, n.4, p.313-20, 2003.

BUDEL, J.M.; DUARTE, M.R.; SANTOS, C.A.M. Morfoanatomia foliar e caulinar de Baccharis dracunculifolia DC., Asteraceae. Latin American Journal of Pharmacy, v.23, n.4, p.477-83, 2004a.

BUDEL, J.M.; DUARTE, M.R.; SANTOS, C.A.M. Stem morpho-anatomy of Baccharis cylindrica (Less.) DC., Asteraceae. Revista Brasileira de Ciências Farmacêuticas, v.40, n.1, p.93-9, 2004b.

BUDEL, J.M. et al. O progresso da pesquisa sobre o gênero Baccharis, Asteraceae: I - estudos Botânicos. Revista Brasileira Farmacognosia, v.15, n.3, p.268271, 2005

BUDEL, J.M. et al. Caracteres anatômicos de folha e caule de Calea uniflora Less., Asteraceae. Revista Brasileira de Farmacognosia, v.16, n.1, p.53-60, 2006.

BUDEL, J.M. et al. Morpho-anatomical study of the cladodes of Homalocladium platycladum (F.J. Muell) L.H. Bailey (Polygonaceae). Revista Brasileira de Farmacognosia, v.17, n.1, p. 39-43, 2007.

BUDEL, J.M,; MATZENBACHER, N.I.; DUARTE, M.R. Genus Baccharis (Asteraceae): a review of chenical and pharmacological studies. In Singh, V. R.; Govil, I.N (Orgs.). Recent Progress in Medicinal PlantsPhhytopharmacology and Therapeutic Values. 3 ed. Houston: Sudium Press LLC, v.21, p1-18, 2008.

BUDEL, J.M.; DUARTE, M.R. Estudo farmacobotânico de folha e caule de Baccharis uncinella DC., Asteraceae. Latin American Journal of Pharmacy, v.27, n.5, p.740-6, 2008a.

BUDEL, J.M.; DUARTE, M.R. Estudo farmacobotânico de partes vegetativas aéreas de Baccharis anomala DC., Asteraceae. Revista Brasileira de Farmacognosia, v.18, supl, p. 761-68, 2008b.

BUDEL, J.M.; DUARTE, M.R. Análise morfoanatômica comparativa de duas espécies de carqueja: Baccharis microcephala DC. e B. trimera (Less.) DC., Asteraceae. Brazilian Journal of Pharmaceutical Sciences, v.45, n.1, 2009.

BUDEL, J. M. et al. Contribution to the pharmacognostic study of Mikania laevigata Sch. Bip. ex Baker "Guaco" for the quality control. Revista Brasileira de Farmacognosia, v.19, n.2, p.545-52, 2009.

BUDEL, J.M.; DUARTE, M.R. Macro and Microscopic characters of the aerial Vegetative organs of carqueja: Baccharis usterii Heering. Brazilian Archives of biology and Technology, v.53, n.1, p.123-131, 2010.

BUDEL, J.M. et al. Composition of essential oils and secretory structures of Baccharis anomala, $B$. megapotamica and $B$. ochracea. Journal of essential oil research, v.24, n.1, p.19-24, 2012.

CASTRO, M.M.; LEITÃO-FILHO, H.F.; MONTEIRO, W.R. Utilização de estruturas secretoras na identificação dos gêneros de Asteraceae de uma vegetação de cerrado. Revista Brasileira de Botânica, v.20, p.163-174, 1997.

COBOS, M.I. et al. Composition and antimicrobial activity of the essential oil of Baccharis notosergila. Planta Medica, v.67, n.1, p.84-6, 2001.

CORTADI, A. et al. Anatomical studies of Baccharis articulata, Baccharis crispa and Baccharis trimera, "Carquejas" used in folk medicine. Pharmaceutical
Biology, v.37, n.5, p.357-65, 1999.

DEMO, M. et al. Antimicrobial activity of essential oils obtained from aromatic plants of Argentina. Pharmaceutical Biology, v.43, n.2, p.129-134, 2005.

DONATO, A.M.; MORRETES, B.L. Estudo anatômico das folhas de Psidium widgrenianum Berg. (Myrtaceae), uma potencial espécie medicinal. Revista Brasileira de Farmácia, v.86, p.65-70, 2005.

ESAU, K. Anatomia das plantas com sementes. São Paulo: Edgard Blucher, 1976.

FARMACOPÉIA brasileira. 4 ed. São Paulo: Atheneu, [1988-2003].

FEDER, N.; O'BRIEN, T. P. Plant microthecnique: some principles and new methods. American Journal of Botany, v. 55, n. 1, p. 123-142, 1968.

FERESIN, G.E. et al. Antimicrobial activity of plants used in tradicional medicine of San Juan province, Argentine. Journal of Ethnopharmacology, v.78, p.103-7, 2001.

FOSTER, A.S. Practical plant anatomy. 2. ed. Princeton: D. Van Nostrand, 1949.

FREIRE, S.E.; URTUBEY, E.; GIULIANO, D.A. Epidermal characters of Baccharis (Asteraceae) species used in traditional medicine. Caldasia, v.29, n.1, p.23-38, 2007.

GIULIANO, D.A. Classificación infragenérica de las espécies argentinas de Baccharis (Asteraceae, Astereae). Darwiniana, v.39, n.1-2, p.131-154, 2001.

JOHANSEN, D.A. Plant microtechnique. New York: McGraw Hill Book, 1940.

JORGE, L.I.F. Botânica aplicada ao controle de qualidade de alimentos e de medicamentos. São Paulo: Atheneu, 2000.

JUDD, W.S. et al. Plant systematics: a phylogenetic approach. Sunderland: Sinauer, 1999.

MATZENBACHER, N.I. et al. Flórula da Fazenda São Maximiano, Guaíba, Rio Grande do Sul, Brasil. Bagé: Ediurcamp, 2011.

METCALFE, C.R.; CHALK, L. Anatomy of dicotyledons: leaves, stem, and woods in relation to taxonomy with notes on economic uses. Oxford: Clarendon Press, 1950. v.2.

MILAN, P.; HAYASHI, A. H.; APPEZZATO-DA-GLÓRIA, B. Comparative leaf morphology and anatomy of three Asteraceae species. Brazilian Archives of Biology and Technology, Curitiba, v.49, n.1, p.135-144, 2006.

MONTANHER, A.B.P.; PIZZOLATTI, M.G.; BRIGHENTE, I.M.C. An Application of the Brine Shrimp Bioassay for General Screening of Brazilian Medicinal Plants. Acta Farm. Bonaerense, v.21, n.3, p.175-178, 2002.

MOREIRA, F.P.M. et al. Flavonóides e triterpenos de Baccharis pseudotenuifolia - Bioatividade sobre Artemia salina. Química Nova, v.26, n.3, p.309-311, 2003.

NAKATA, P.A. Advances in our understanding of calcium oxalate crystal formation and function in plants. Plant Science, v.164, p.901-9, 2003.

O'BRIEN, T. P., FEDER, N.; MCCULLY, M. E. Polychromatic staining of plant cell walls by toluidine blue $O$. Protoplasma, v.59, n.2, p.368-73, 1964.

OLIVEIRA, F.; LÚCIA, M.; GARCIA, L.O. Caracterização farmacognóstica da droga e do extrato fluido de mentrasto - Ageratum conyzoides L. Lecta, v.11, n.1, p.63-100, 1993.

OLIVEIRA, S.Q. et al. Antioxidant activity of Baccharis articulata extracts: isolation of a new compound with

Rev. Bras. PI. Med., Campinas, v.15, n.4, p.566-574, 2013. 
antioxidant activity. Free Radical Research, v.37, n.5, p.555-9, 2003.

OLIVEIRA, A.S. et al. Checklist do gênero Baccharis L. para o Brasil (Asteraceae - Astereae). Balduinia, v.9, p.17-27, 2006.

PAGNI, A.M.; MASINI, A. Morphology, distribution and histochemistry structures in vegetative organs of Santolina leucantha Bertol. (Asteraceae). Israel Journal Plant Science, v.49, p.257-63, 1999.

PEGORINI, F.; MARANHO, L.T.; ROCHA, L.D. Organização estrutural das folhas de Baccharis dracunculifolia DC., Asteraceae. Revista Brasileira de Farmácia, v.89, n.3, p.272-275, 2008.

PETENATTI, E.M. et al. Medicamentos herbarios en el centro-oeste Argentino. VI. Caracterización y control de calidad de dos espécies de "carquejas": Baccharis sagittalis y $B$. triangularis (Asteraceae). Latin American Journal of Pharmacy, v.26, n.2, p.201-208, 2007.

PETERSON, R.L.; VERMEER, J. Histochemistry of trichomes. In: Biology and chemistry of plant trichomes. New York: Plenum Press, p.71- 94, 1984.

RODRIGUEZ, M.V.; GATTUSO, S.; GATTUSO, M. Baccharis crispa y Baccharis trimera (Asteraceae): revisión y nuevos aportes para su normalización micrográfica. Latin American Journal of Pharmacy, v.27, n.3, p.387-397, 2008.

ROESER, K. R. Die Nadel der SchwarzkieferMassenprodukt und Kunstwerk der Natur. Mikrokosmos, v.61, n.2, p. 33-36, 1972.

SÁ, M. de F.A.; NEVES, L. de J. Contribuição ao estudo das plantas medicinais Baccharis myriocephala DC. Revista Brasileira de Farmácia, v.77, n.3, p.88-96,
1996.

SASS, J.E. Botanical microtechnique. 2 ed. Ames: lowa State College, 1951

SCHENKEL, E.P. et al. Screening of Brazilian plants for the presence of peroxides. Revista Brasileira de Ciências Farmacêuticas, v.38, n.2, p.191-6, 2002.

SIMÕES-PIRES, C.A. et al. Investigation of the essential oil from eight species of Baccharis belonging to sect. Caulopterae (Asteraceae, Astereae): a taxonomic approach. Plant Systematics and Evolution, v.253, p.23-32, 2005.

SOUZA, W. Técnicas básicas de microscopia eletrônica aplicadas às Ciências Biológicas. Rio de Janeiro: Sociedade Brasileira de Microscopia Eletrônica, 1998.

SOUZA, V.C.; LORENZI, H. Botânica sistemática: guia ilustrado para identificação das famílias de angiospermas da flora brasileira, baseado em APG II. São Paulo: Instituto Plantarum, 2005.

TOIGO, L. et al. Caracterização farmacobotânica, estudo do óleo essencial e atividade antimicrobiana da erva de São Simão Vernonia scorpioides (Lam.) Pers. Revista Brasileira de Farmácia, v.85, n.2, p. 49-55, 2004.

WERKER, E.; FAHN, A. Secretory hairs of Inula viscola (L.) Ait.: development, ultrastructure, and secretion. Botanical Gazette, v.142, p.461-76, 1981.

WERKER, E. Trichome diversity and development. In: HALLAHAN, D.L.; GRAY, J.C. Plant trichomes. London: Academic, p.1-35, 2000.

VERDI, L.G.; BRIGHENTE, M.C.; PIZZOLATTI, M.G. Gênero Baccharis (ASTERACEAE): Aspectos químicos, econômicos e biológicos. Química Nova, v.28, n.1, p.85-94, 2005. 